\title{
Extensão Universitária na Formação em Saúde
}

\author{
University Extension in Health Training
}

Extensión de la Universidad en la Formación de la Salud

Josineide Francisco Sampaio $^{1}$

Diante da complexidade do processo saúde-doença e da necessidade de se enfrentar a realidade socioeconômica e sanitária, aliadas as mudanças da direção da formação em saúde evocadas pelas Diretrizes Nacionais para os Cursos da Área da Saúde, a partir de 2001, a reflexão sobre a temática da extensão universitária nesse campo de formação adquire significado e relevância, visto que as ações extensionistas constituem uma dimensão importante no processo de formação, por possibilitar experiências ampliadas, além da sala de aula, diretamente vinculadas à realidade dos serviços e comunidades, nos quais exerce-se a atuação profissional.
De acordo com o Plano Nacional de Extensão Universitária, elaborado no Fórum Pró-Reitores de Extensão das Universidades Públicas Brasileiras ${ }^{(1)}$, a extensão universitária é uma atividade acadêmica que tem a função de promover a comunicação entre universidade e seu meio, atuando junto às problemáticas da sociedade. Nesse sentido, a Extensão universitária constitui-se em um processo educativo, cultural e científico que articula o ensino e a pesquisa de forma indissociável, viabilizando uma formação intrinsecamente envolvida e comprometida com a realidade da sociedade.

O livro ${ }^{(2)}$ apresenta uma diversidade de temas e experiências

${ }^{1}$ Sociológa. Doutora em Ciências da Saúde. Docente na Faculdade de Medicina (FAMED/UFAL). Autora correspondente: Campus A.C. Simões. Av. Lourival Melo Mota, s/n - Tabuleiro do Martins, Maceió - AL, 57072-900. E-mail: josineide.sampaio@famed.ufal.br 
desenvolvidas por docentes e discentes da Faculdade de Medicina da Universidade Federal de Alagoas, com diferentes cursos da área da saúde, em vários arranjos metodológicos e estratégicos, junto aos profissionais, estudantes e comunidades, revelando desejos e compromissos com uma formação em saúde pautada na ética e na humanização, em sintonia com as Diretrizes Curriculares e a Política Nacional de Extensão Universitária.

Considerando a indissociabilidade da extensão com o ensino e a pesquisa, o seu conteúdo foi distribuído em duas seções. A primeira, apresenta artigos que trazem informações sobre resultados relacionados às ações de extensão na literatura científica, junto aos serviços de saúde, profissionais de saúde, discentes e usuários, instituições de ensino da rede pública e privada de ensino médio e fundamental e comunidades.

Desse modo, traz dois estudos de revisão de literatura: sendo um, sobre as contribuições da extensão universitária para a formação profissional em saúde; e outro sobre os pontos e contrapontos do parto humanizado no Brasil. Em relação à formação profissional em saúde, foram apresentados três estudos: sendo um, sobre os resultados alcançados pelo
Projeto de Extensão Hanseníase na Comunidade junto aos estudantes de ensino superior da área da saúde e aos profissionais da Atenção Básica de Maceió; outro sobre as oportunidades de aprendizagem discente no Estágio Rural em Arapiraca sob a perspectiva da Clínica Ampliada; e ainda um, sobre o conhecimento e a motivação para o aprendizado sobre reanimação cardiopulmonar em profissionais de enfermagem do Hospital Universitário Prof. Alberto Antunes HUPAA/UFAL. Nesta seção do livro, também foram apresentados estudos sobre o perfil socioeconômico e o grau de satisfação dos usuários assistidos em Unidades Básicas de Saúde; a prática educativa em reanimação cardiopulmonar desenvolvida junto a alunos de ensino médio em escola pública e privada em Maceió; a qualidade de vida de dependentes químicos em processo de reabilitação e sobre o estado nutricional de adultos e idosos participantes do Projeto Ensinar e Aprender Desenvolvendo Ações de Saúde Coletiva.

$\mathrm{Na}$ segunda seção, são apresentados os relatos de experiência de docentes e, principalmente, discentes sobre o significado da vivência e do aprendizado no processo de formação e atuação profissional em participarem de 
diferentes atividades de extensão como programas, projetos e ligas acadêmicas. Nela, estão inscritos a percepção e os sentimentos impressos na memória, embora recente, do que significou para os autores a extensão universitária e a sua contribuição para sua formação e atuação como profissional de saúde.

Esse livro apresenta uma temática relevante e atual, considerando as mudanças didático-pedagógicas e curriculares, em curso, nas universidades públicas, especialmente, na Universidade Federal de Alagoas, por contribuir com o debate sobre o papel da extensão universitária na formação em saúde, e divulgar no meio acadêmico as ações desenvolvidas, estimular a sistematização, a organização e a ampliação da participação de todos no desenvolvimento das ações extensionistas.

\section{Referências}

1. Ministério da Educação. Fórum de Pró-Reitores de Extensão das Universidades Públicas Brasileiras e SESu/MEC. Plano Nacional de Extensão Universitária. Edição Atualizada Brasil 2000/2001, Brasília, 2002a.

2. Sampaio JF, Lima ACS, Bittencourt CCBLD, Soares FJP, Oliveira LJ, Vieira de. (Organizadores).
A Extensão Universitária na Formação em Saúde. Maceió: Edufal; 2015. 